\title{
ANÁLISE DA INFLUÊNCIA DE TEORES DE SUBSTITUIÇÃO DE AGREGADOS DE RESÍDUO DE CONSTRUÇÃO E DEMOLIÇÃO EM CONCRETOS UTILIZANDO A ANÁLISE DE COMPONENTES PRINCIPAIS Karine Duque Cruz ${ }^{1}$; Koji de Jesus Nagahama ${ }^{2}$ \\ 1. Bolsista PROBIC/UEFS, Graduando em Engenharia Civil, Universidade Estadual de Feira de Santana, e-mail: karine-duque@hotmail.com \\ 2. Orientador, Departamento de Tecnologia, Universidade Estadual de Feira de Santana, e-mail: koji@ uefs.br
}

PALAVRAS-CHAVE: resíduo de construção e demolição; concreto reciclado; análise de componentes principais

\section{INTRODUÇÃO}

$\mathrm{Na}$ tentativa de redução do impacto causado ao ambiente pelas atividades humanas todos os segmentos da sociedade têm buscado repensar suas estratégias de produção. A construção civil é um dos segmentos industriais que mais consome recursos naturais. $\mathrm{O}$ desenvolvimento de novos materiais a base de cimento vem sendo estimulado pela capacidade de incorporação de resíduos sólidos ao concreto, o que tende a minimizar o impacto ambiental destes resíduos e aprimorar este material, abrindo campo para novas aplicações.

Para modelagem foram utilizadas Redes Neurais Artificiais (RNA), que são um dos tipos de técnicas de inteligência computacional, em que seutiliza a denominada computação natural para a solução dos problemas e podem ser aplicadasem tarefas em que se tem uma base de dados de um problema específico.Para preparação dos dados foi utilizado o método de modelagem numérica Análise de Componentes Principais (ACP), a qual é associada à ideia de redução de massa de dados, com menor perda possível da informação.

\section{METODOLOGIA}

A pesquisa foi realizada utilizando o software Matlab, onde as RNA foram desenvolvidas. Nesta pesquisa, além das RNA, aplicou-se também o método de modelagem estatística da ACP. Os dados experimentais foram coletados dos trabalhos de Leite (2001), Vieira (2003), Cabral (2007), Lovato (2007) e Lima (2008). Os resultados foram agrupados para montagem de uma RNA geral, que permitisse avaliar as propriedades de Resistência à compressão e Módulo de Deformação do concreto reciclado (concreto contendo agregados graúdos e miúdos oriundos de resíduos de construção e demolição).

Tabela 1: Nomenclatura das variáveis de entrada

\begin{tabular}{cl|cl}
\hline Variável & \multicolumn{1}{c|}{ Nomenclatura } & Variável & \multicolumn{1}{c}{ Nomenclatura } \\
\hline RAC & Relação água-cimento & FGR & Módulo de finura do agregado graúdo reciclado \\
PAM & Percentual de agregado miúdo reciclado & DMN & Dimensão máxima do agregado miúdo natural \\
PAG & Percentual de agregado graúdo reciclado & DMR & Dimensão máxima do agregado miúdo reciclado \\
ARG & Percentual de agregado reciclado de & DGN & Dimensão máxima do agregado graúdo natural \\
COC & Percentual de agregado reciclado de & DGR & Dimensão máxima do agregado graúdo reciclado \\
CER & Percentual de agregado reciclado de & CIM & Quantidade de cimento \\
OUT & Percentual de outros materiais & ADT & Percentual de aditivo \\
TAR & Teor de argamassa & CAM & Taxa de compensação do agregado miúdo reciclado \\
TAG & Teor de agregados & CAG & Taxa de compensação do agregado graúdo reciclado \\
FMN & Módulo de finura do agregado miúdo & ABM & Taxa de absorção do agregado miúdo reciclado \\
FMR & Módulo de finura do agregado miúdo & ABG & Taxa de absorção do agregado graúdo reciclado \\
FGN & Módulo de finura do agregado graúdo & IDE & Idade \\
\hline
\end{tabular}

Os dados foram preparados utilizando o método de modelagem ACP.Modelaram-se dois tipos de RNA, uma em que todos os dados foram destinados apenas para a fase de treinamento (RNA-1) e outra em que $70 \%$ dos dados foram utilizados na fase de 
treinamento e $30 \%$ dos dados utilizados na fase de validação (RNA-2). As RNA utilizadas foram do tipo feedforward multicamadas. $\mathrm{O}$ algoritmo de aprendizado adotado foi o backpropagation, e associoado ao algoritimo backpropagationo $\mathrm{o}$ algoritmo de treinamento Levenberg Marquardt (LM).

Para as propriedades analisadas, a RNA que apresentou maior valor do coeficiente de determinação $\left(\mathrm{R}^{2}\right)$ é a que possui a maior confiabilidade. Além da verificação do coeficiente de determinação utilizou-se como critério de escolha da RNA, o histograma de distribuição de erros pois um elevado coeficiente de determinação, por si só, não garante erros pequenos.

\section{RESULTADOS E DISCUSSÃO}

Para a propriedade da resistência à compressão, aos 3, 7, 28 e 91 dias, de concretos contendo RCD, o banco de dados possui um total de 1180 resultados e 24 variáveis, as quais estão descritas na Tabela 1.

Inicialmente foram modeladas RNA com todas as variáveis apresentadas na Tabela 1. Referente à RNA-1 com 9 neurônios, sendo o coeficiente de determinação igual a 0,960 , $86 \%$ dos dados apresentaram erros numa faixa de $-10 \%$ a $10 \%$. Sendo modelo satisfatório para predição de resistência à compressão contendo RDC.

Após aplicar a técnica ACP, as 24 variáveis foram reduzidas para 10, as quais explicam 98,1\% da variância total do dados. As variáveis FMN e CAG foram as que apresentaram maior influência com, respectivamente, $36,1 \%$ e $22 \%$. Em seguida tem-se CAM com 11,1\%, DGR com 7,8\%, CER com 5,4\%, DMR com 4,7\%, IDE com 3,7\%, PAG com 3,1\%, PAM com 2,7\% e COC com 1,5\%. As RNA foram modeladas,então, com 10 variáveis de entrada.

Para nenhuma das RNA modeladas, o valor de $\mathrm{R}^{2}$ apresentou-se maior que 0,95 . $\mathrm{O}$ maior valor encontrado foi 0,648 , na RNA em que todos os dados foram utilizados apenas na fase de treinamento (RNA-1), utilizando-se 10 neurônios. A qual foi adotada neste trabalho para a predição da resistência à compressão de concretos contendo RCD. Esse modelo está ilustrado na Equação (1) e Equação (2). Sendo o erro médio para esta RNA é de $-9,20382 \%$.

$$
\begin{aligned}
& F C=-\frac{210,6041}{e^{k_{1}+1}}+\frac{1301,1517}{e^{k_{2}}}+\frac{16,472}{e^{k_{3}}}-\frac{667,6875}{e^{k_{4}}}+\frac{2014,5684}{e^{k_{5}}}+\frac{160,4061}{e^{k_{6}}}+\frac{72,8222}{e^{k_{7}}}+\frac{1177,4028}{e^{k_{8}}}+\frac{164,5601}{e^{k_{9}}}+ \\
& \frac{1238,3274}{e^{k_{10}}}+2179,8737
\end{aligned}
$$

Onde:

$$
k_{j}=\sum_{i=0}^{10} M_{i 0} x M_{i j} \therefore j=1 . .10
$$

Tabela 2: Coeficientes M da Equação (1)

\begin{tabular}{ccccccccccc}
\multicolumn{10}{c}{ Tabela 2 : Coeficientes M da Equação (1) } \\
\hline PAM & 1 & 2 & 3 & 4 & 5 & 6 & 7 & 8 & 9 & 10 \\
PAG & 0,0137 & $-1,54 \mathrm{E}-04$ & $-8,54 \mathrm{E}-03$ & $-0,0571$ & $-0,0312$ & $-0,0128$ & 0,0173 & 0,0347 & $-4,60 \mathrm{E}-03$ & $8,76 \mathrm{E}-$ \\
COC & $-0,0926$ & $-2,98 \mathrm{E}-03$ & 0,1149 & $-2,41 \mathrm{E}-03$ & $-7,99 \mathrm{E}-04$ & $-0,0350$ & 0,0211 & $5,69 \mathrm{E}-04$ & $-0,0110$ & $-0,0122$ \\
CER & $-0,1088$ & 0,0206 & $-4,0140$ & $-0,0185$ & 0,0197 & 0,6546 & 0,1283 & $-0,0353$ & $-1,1331$ & $-0,0144$ \\
FMN & 3,8216 & 5,8661 & $-13,6322$ & $-11,3919$ & $-8,6815$ & $-58,6276$ & 7,8234 & $-6,9578$ & 6,8909 & 22,259 \\
DMR & 146,5318 & $-242,6314$ & $-352,5512$ & 162,3804 & 88,9007 & 209,9085 & $-328,2419$ & $-27,8648$ & $-438,6335$ & 17,515 \\
DGR & $-0,7923$ & $-0,4078$ & $-0,8150$ & 0,8488 & 0,2853 & $-0,4671$ & $-0,5516$ & $-0,6373$ & $-0,9270$ & 2,0487 \\
CAM & 0,4769 & $-0,0254$ & 2,4456 & 0,3404 & 0,3227 & 0,9653 & $-0,2194$ & 0,4912 & 0,7938 & $-0,2647$ \\
CAG & $-0,1330$ & 0,0144 & $-0,2643$ & $-0,1619$ & $-0,1230$ & 0,3295 & $-0,0132$ & $-0,1599$ & $-0,5491$ & $-0,6237$ \\
IDE & $5,92 \mathrm{E}-03$ & $-0,1665$ & $-0,0949$ & $6,38 \mathrm{E}-05$ & $-3,25 \mathrm{E}-05$ & $-0,0109$ & $-4,17 \mathrm{E}-03$ & $-7,88 \mathrm{E}-05$ & $4,02 \mathrm{E}-03$ & 0,4780 \\
Constan- & $-719,861$ & 1149,630 & 1655,876 & $-767,065$ & $-416,1$ & $-889,883$ & 1573,165 & 142,0849 & 2071,488 & $-134,07$ \\
te & 5 & 6 & $-0,0755$ & $-0,0560$ & $-0,6697$ & $-0,0184$ & 0,0680 & 1,3172 & $-0,1307$ \\
\hline
\end{tabular}




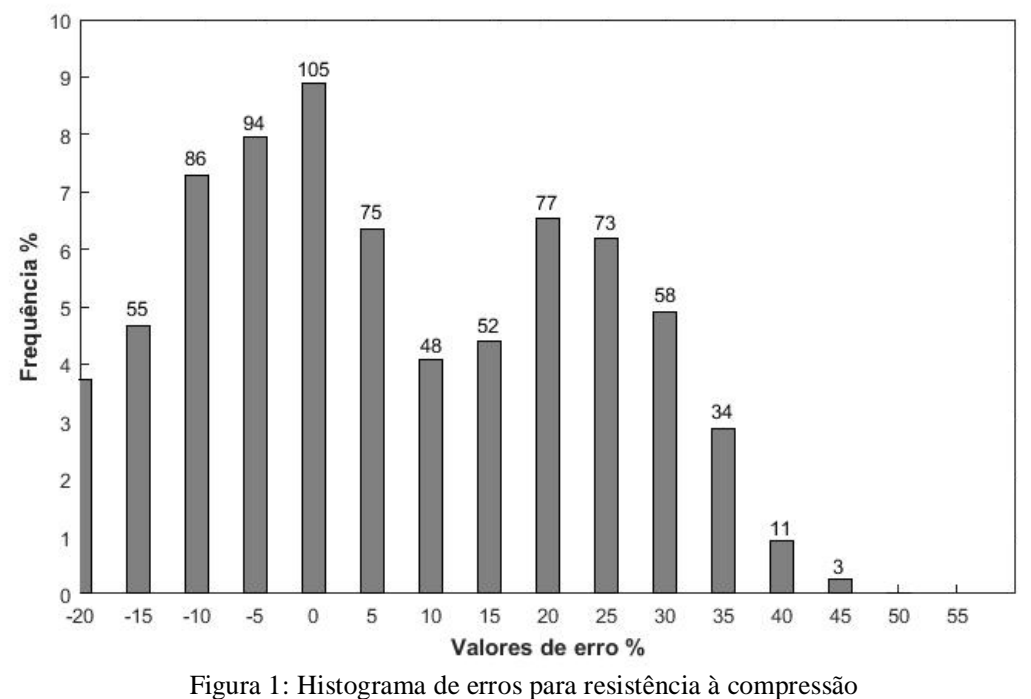

Foi elaborado o histograma dos erros obtidos da comparação dos resultados gerados pela RNA com os dados experimentais, ilustrado na Figura 1. Observa-se que 34,6\% dos dados apresentam erros numa faixa de $-10 \%$ a $10 \%$. Esse resultado implica que o modelo gerado não é considerado satisfatório para a predição de resistência à compressão de concreto contendo RCD. Fazendo uma comparação entre os modelos gerados, sem e com a utilização de ACP, podemos observar que o modelo é bom e que a aplicação da ACP sem os devidos cuidados pode prejudicar o modelo, pois para um determinado conjunto de dados variáveis que tem importância podem acabar sendo desprezadas.

Para a propriedade do módulo de elasticidade de concretos contendo RCD, o banco de dados possui um total de 314 resultados e 23 variáveis, as quais estão descritas na Tabela 1, exceto a variável IDE.

Inicialmente foram modeladas RNA com todas as variáveis apresentadas na Tabela 1, exceto a variável IDE. Referente à RNA-1 com 7 neurônios $90 \%$ dos dados apresentaram erros numa faixa de $-10 \%$ a $10 \%$. Este resultado implica que o modelo gerado é satisfatório para predição de módulo de elasticidade contendo RDC.

Após aplicar a técnica ACP as 23 variáveis foram reduzidas para 9, as quais explicam 99,2\% da variância total do dados, como ilustra a Figura 5. As variáveis DGN e FMN foram as que apresentaram maior influência com, respectivamente, $41,1 \%$ e $21,1 \%$. Em seguida tem-se OUT com 11,7\%, CIM com 9,6\%, DMR com 6,4\%, PAM com 3,4\%, PAG com $2,9 \%$, ABG com $1,6 \%$ e ADT com 1,3\%. As RNA foram modeladas, então, com 9 variáveis de entrada.

A RNA-1com 7 neurônios foi adotada neste trabalho para a predição do módulo de elasticidade de concretos contendo RCD. Esse modeloestá ilustradona Equação (3) e Equação (4). Sendo o erro médio para esta RNA é de -0,66686\%.

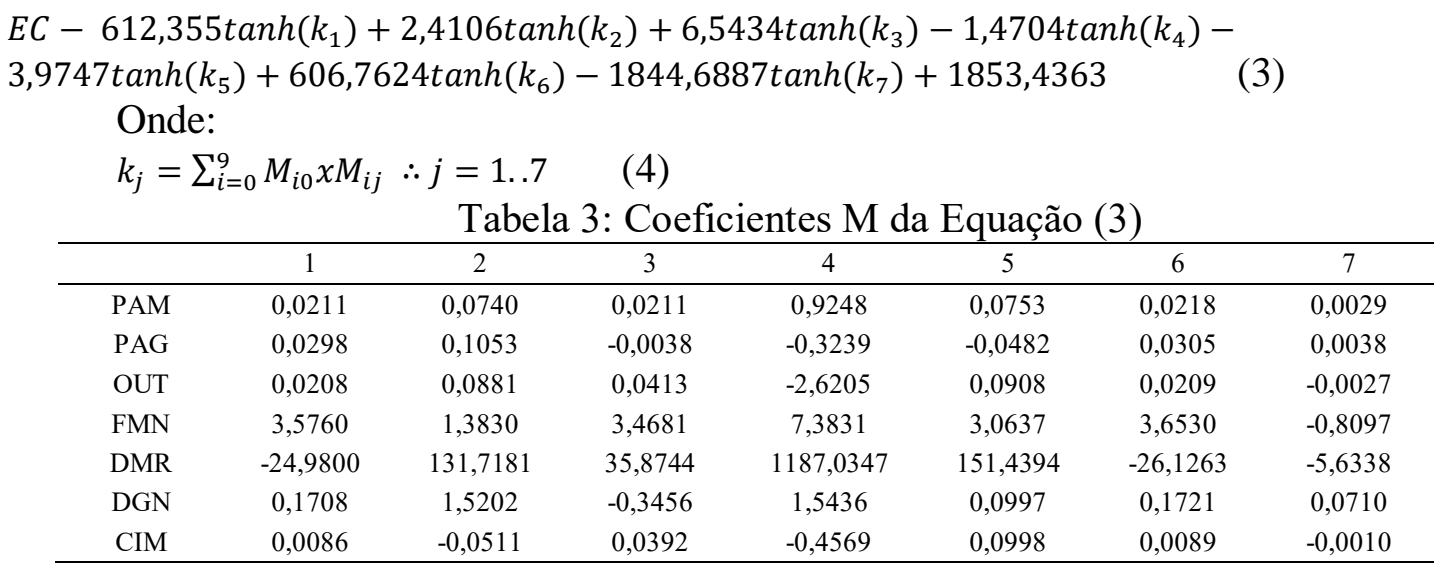




\begin{tabular}{cccccccc}
\hline ADT & $-0,1919$ & 0,7071 & 0,7041 & $-34,6936$ & 0,4556 & $-0,1855$ & 0,0446 \\
ABG & $-0,0812$ & $-0,8927$ & $-0,1732$ & 1,7375 & $-0,4848$ & $-0,0809$ & 0,0289 \\
Constante & 101,3850 & $-651,2012$ & $-186,4218$ & $-5532,3707$ & $-759,5846$ & 106,4357 & 30,8389 \\
\hline
\end{tabular}

Foi elaborado o histograma dos erros obtidos da comparação dos resultados gerados pela RNA com os dados experimentais. Observa-se que $72 \%$ dos dados apresentam erros numa faixa de $-5 \%$ a $5 \%$, gerando assim um modelo que pode ser considerado satisfatório para a predição do módulo de elasticidade de concreto contendo RCD.

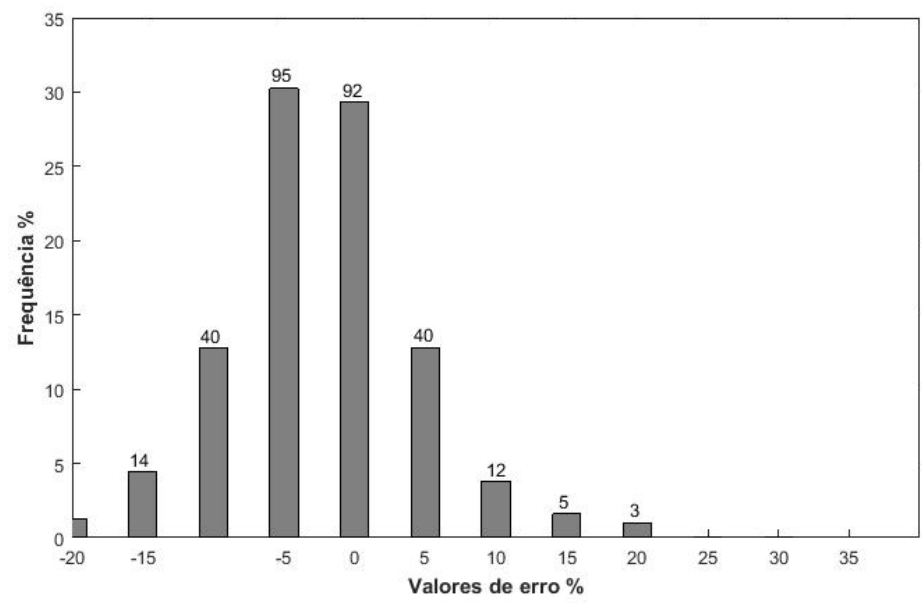

Figura 2: Histograma de erros para módulo de elasticidade

\section{CONSIDERAÇÕES FINAIS}

Neste trabalho foi avaliada a influência de teores de substituição de agregados de resíduo de construção e demolição em concretos utilizando a ACPe desenvolvidos modelos baseados em RNA para predizer as propriedades de resistência à compressão e módulo de elasticidade do concreto contendo RCD.

Embora a técnica ACP consista na ideia de redução de massa de dados com menor perda possível da informação, a mesma avalia apenas a variância dos dados das variáveis. Porém, variáveis que possuem grande importância podem apresentar baixa variância pois isso depende bastante do conjunto de dados analisados.

Este estudo permite a obtenção de equações de predição das propriedades de resistência à compressão e módulo de elasticidade de concreto contendo RCD, considerando uma quantidade menor de variáveis, as quais explicam mais de $90 \%$ da variância total. Ressalta-se que as equações não possuem o objetivo de substituir os ensaios realizados em laboratório que são importantes para confirmar os resultados obtidos nos modelos.

\section{REFERÊNCIAS}

CABRAL, A. E. B. 2007. Modelagem de propriedades mecânicas e de durabilidade de concretos produzidos com agregados reciclados, considerando-se a variabilidade da composição do RCD. São Carlos, 280p. Tese (Doutorado) - Escola de Engenharia de São Carlos Universidade de São Paulo.

LEITE, M. B. 2001. Avaliação de propriedades mecânicas de concretos produzidos com agregados reciclados de resíduos de construção e demolição. Porto Alegre, 270p. Tese (Doutorado).

LIMA, M. B. L.; MOURA, W. A.; LIMA, P. R. L.; GONÇALVES, J. P.; MARINS, C. C. 2007. Avaliação de propriedades físicas de concretos reciclados de resíduos de construção e demolição. Anais do $49^{\circ}$ Congresso Brasileiro do Concreto. Ibracon.

LOVATO, P. S. 2007. Verificação dos parâmetros de controle de agregados reciclados de resíduos de construção e demolição para utilização em concreto. Porto Alegre, 182p. Dissertação (mestrado) - Universidade Federal do Rio Grande do Sul.

VIEIRA, F. M. P.; KULAKOWSKI, M. P.; DAL MOLIN, D. C. C.; VILELA, A. C. F. 2003. Adição de sílica ativa ao concreto: efeito benéfico ou prejudicial na corrosão das armaduras desencadeada por carbonatação?. In: $45^{\circ}$ Congresso Brasileiro do Concreto, Vitória. 